\title{
Issues of Access, Equity, and Quality in Early Childhood Development Programmes in Zimbabwe
}

\author{
Rose M. Mugwenia
}

\begin{abstract}
The paper sought to explore issues of access, equity, and quality in the early childhood development (ECD) sub-sector in Zimbabwe. The massive expansion of ECD services prompted the author to undertake the study. Data were collected using focus group discussions, individual interviews, document analysis, and observations. Information from literature, research reports, policies, and practices was also analyzed in order to establish the state of affairs in the provision of ECD. The data were analyzed using theme identification methods to solicit emerging issues. Generally, it was found that on issues of access, equity, and quality in ECD in Zimbabwe, there is a quality-quantity dilemma with qualitative progress less conspicuous than quantitative progress. The resultant specific challenges include: large teacher-child ratio; lack of parental involvement, lack of trained ECD specialists with expertise in using a play-based curriculum; and shortage of equipment, material resources, and age appropriate infrastructure. In most ECD settings, there were inadequate health and nutrition provisions. Water, sanitation and health (WASH) facilities were found to be insufficient in most centres. The study recommended that there is need for: equal access to quality early childhood education; provision of infrastructure, provision of ability and age appropriate resources; and health, sanitation, and nutrition services especially in rural settings. Overall, ECD programmes in Zimbabwe should strive to attain quality more than quantity services. The need to train more early childhood specialists who would drive the ECD sub-sector is emphasized.
\end{abstract}

\section{Keywords}

Access, equity, quality, quantity, early childhood development

Zimbabwe gained its independence in 1980, after almost 100 years of British colonial rule. The colonial era was built on white supremacy, racial segregation, institutionalized violence, and oppression of the majority African population by the white minority. The new government was committed to creation of a socialist state guided by the principles of social justice and equity. Education was declared a human right. It was regarded as a potent tool for social and economic transformation. The provision of early childhood education was therefore regarded as a compensatory act for those who had been denied the opportunity by successive regimes of the colonial era. Later, the expansion of provisions and effective implementation of early childhood education were faced with an unstable macro-economic environment and the fall of the Zimbabwe dollar against major currencies.

aGreat Zimbabwe University, Zimbabwe

\section{Correspondent Author:}

Rose M. Mugweni, Department of Educational Foundations, P. 0. Box 1235, Masvingo, Zimbabwe 
The Ministry of Primary and Secondary Education (MOPSE) formally known as Ministry of Education, Sport, Arts and Culture (MoESAC) used the Education Act of 1987 revised 1996 as the basis for formulation of Statutory Instrument (SI) 106, Secretary's Circulars 14 of 2004 and 12 of 2005. Under these circulars, primary schools are mandated to attach at least two early childhood development classes (ECD A and ECD B). The policy framework aims to initially improve 4- to 5-year-old children's equitable access to quality basic education in ECD programmes. All the policy instruments-circulars 14 of 2004, 12 of 2005, and the relevant SI 106, are consistent on enhancing access, equity, and quality in ECD to the entire country. Henceforth, these policy tools (Circulars 14 of 2004, 12 of 2005, and SI 106) outline the legal and administrative framework for the provision of quality ECD in Zimbabwe. Regardless of these positive developments in ECD, there seems to be lack of quality services in ECD. Proceedings below are definitions of key terms in this study, which are: access, equity, quality, and quantity.

Access is the availability and provision of the programmes and services for all young children. It is the process of ensuring equal opportunity and allocation of resources and services in a fair, consistent, and inclusive manner irrespective of an individual's or group's cultural or linguistic background, their religion or spiritual beliefs, socio-economic status, gender, age, or abilities (Britto, Yoshikwa, and Boller 2011). Access can be understood as the ability to attain entry and the right to attend an educational institution (Tinto 2012). Access is the availability and provision of programmes and services for children (Britto et al. 2011). It is a way that every young child gets opportunity to education. Access should be free of any form of discrimination irrespective of a child's country of birth, language, culture, race, or religion. It can be simply conceptualized as right of entry.

Equity refers to an opportunity distributed fairly for utilization of talent, the development of skills and abilities, which contribute to development of the society (Zafeirakou 2012). Tinto (2012) viewed equity as a human right imperative for all children so as to have a reasonable opportunity to develop their capacities, and to participate fully in society. It is also referred to as fairness. It is based on a balance of two different sets of rights, that is, every child's right to participate, and that of being presented equally within a particular environment (Thomas 2010). Hence, equity refers to judgements about whether or not a given action or a particular state of affairs is just. In the context of this study, equity can be viewed as fairness, both in the collection and distribution of resources for educational purposes in ECD.

Quality is defined as the critical ingredient of programmes linked with the child's outcome. This is a dynamic, flexible, and adaptable construct that contours itself across cultures, settings and types of interventions (Santrock 2005). It involves the whole child by considering the child's physical, cognitive, social, and emotional development. It should be noted that quality is not seen but is measured against certain standards (Santrock 2005). Statutory Instrument 106 of 2005 stipulates that schools are expected to provide quality programmes aimed at ensuring that young children grow up healthily and are protected from harm. Thus, the concept of quality places emphasis on the value of the maintenance of high standards.

Early childhood development (ECD) is viewed as a comprehensive approach to policies and programmes for children from conception to eight years old (Vernez, Krop, and Rydell 1999). ECD is further viewed by Zafeirakou (2012) as a multi-dimensional process containing four basic interconnected areas of child development (birth to eight years old) namely physical, cognitive, linguistic, and socio-emotional. ECD encompasses early learning and stimulation, health, education, nutrition, hygiene, and sanitation. It is seen as socialization, education, readiness for school and the provision of basic health care and adequate nutrition, nurturing and stimulation 
within a caring environment for children aged zero to eight years old (Hill and Chalaux 2011). Precisely, ECD is a multi-sectoral programme which requires full cooperation among key sectors including government ministries, non-governmental organizations, the private sector, and communities for providing quality services to young children.

The National Association of the Education of Young Children (NAEYC) established a list of criteria for high quality early childhood programmes. The criterion serves as a standard control measure of excellence. In Zimbabwe, access has been provided to a great extent. However, the issue of quality falls far short of the desired level. Gordon and Browne (2012) averred that poor infrastructure, high teacher-child ratio, untrained professionals, safe stimulating environments, lack of nutritious food and deficient health provisions are poor indicators for the desire to attain quality ECD. The international policy guidelines such as the Millennium Development Goals (MDGs) and the Education for All (EFA) (Hyde and Miske 2000; Nwonwu 2008; Mugweni and Dakwa 2013) view country enrolment level as an indicator for quality progress. Focusing on access in programming is a limited approach to attaining quality in ECD services.

Reviewed literature (Zafeirakou 2012; Mugweni 2011; Young 2002) identified the following factors as the hallmarks of high quality in the provision of early childhood development:

(1) A holistic child development curriculum;

(2) Low enrolment limits with teaching/caregiving teams assigned to each class;

(3) Teaching assistants, teachers/caregiver ratio of 1:20 is used in the Zimbabwean early ECD sub-sector;

(4) Specialist staff trained in early childhood development;

(5) Supervisory support and in-service training for a child development curriculum;

(6) Involvement of parents as partners with ECD A and ECD B programme staff;
(7) Sensitivity to the non-educational needs of the child and family;

(8) Developmentally appropriate practice (DAP) in facilitation of learning through play, assessment, and evaluation procedures;

(9) Age appropriate resources.

From the literature study, it can be acknowledged that quality is a double defined element of education. It is seen as a constructed, subjective concept, related to values, beliefs, and interests (Zafeirakou 2012). Quality involves high standards that are expected in an institution or sector (Silverman 2010). There is need to have quality in the ECD curriculum content and methodology. Young (2002) posited that the relevance of an ECD curriculum requires greater attention which therefore requires greater analysis of key components.

\section{MATERIALS AND METHODS}

The author undertook a qualitative study based on focus group discussions, individual interviews, observations, and document analysis as espoused by Creswell (2007). Information from literature, research reports, policies, and practices was also analyzed to establish the state of affairs regarding access, equity, and quality issues in the provision of ECD in Zimbabwe. Data were solicited from a purposefully selected sample of 35 ECD specialist teachers from all 10 provinces in Zimbabwe who were undertaking a Bachelor of Education, ECD Degree in 2013. It was justified to collect data from the ECD teachers because they were found to give reliable information since they were operating in the various contexts throughout the country. Due to limited time, a set of semi-structured questions were used to guide the participants in their volunteering of information in an attempt to identify issues on access, equity, quantity, and quality in the provision of ECD in Zimbabwe.

Data analysis was conducted according to descriptive analysis and a coding system as outlined by De Vos et al. (2005). Relevant themes, categories, 
and sub-categories were generated from the data to allow a presentation, synthesis, and discussion of the results. Tesch's method of data analysis according to Creswell (1994: 154-155; 2003) and Mugweni (2012: 112) was used to analyze all the data from personal accounts and focus group interviews. According to Hancock and Algozzine (2006: 16), the strategy created mental images that brought to life the complexities of the variables inherent in how quality, access, and equity is realized in the delivery of ECD in the different contexts in Zimbabwe. In presenting data, the author chose to consider the results and findings in relation to the reviewed literature and research questions.

\section{RESULTS AND DISCUSSION}

Based on the information from the data, following below is a discussion of the findings of the study.

There Was Generally Lack of Equipment, Material Resources and Infrastructure in Most of the Early Childhood Centres Explored

Despite phenomenal expansion of the educational sector after independence, access to ECD remains inadequate in some parts of the country. It was observed that access to ECD provisions is better in urban areas due to the mushrooming of nurseries, day care centres, and ECD centres in primary schools. In rural areas, children access early childhood education in centres attached to primary schools. Mere attachment of two ECD classes to existing primary schools with inappropriate infrastructure lacked quality services. Attaching ECD classes to existing primary schools failed to meet the hallmarks of quality ECD provision outlined in SI 106 of 2005 where benchmarks for quality curriculum, infrastructure, and teacher qualification are outlined.

Results also reveal that in some settings, there are insufficient play materials and equipment. Also, rural, resettlement, and farm ECD centres remain generally poorly equipped. They have inadequate buildings, furniture, and appropriate play materials. In some areas, not much has been done in ECD due to attitudes and limited resources. Shizha and Kariwo (2012) stated that in the mid-1980s, the government funded contraction of one model ECD centre per province. Later from 2004 onwards, every primary school was mandated to have at least two ECD classes. Compared to the population consisting of cohort of 3- to 5-year-old children, these provisions remain inadequate. As a result of few centres, most children in Zimbabwe do not have access to ECD services.

Zafeirakou (2012) observed that the Zimbabwean ECD programme was a hurried and over ambitious programme, because a visit to most preschools including those attached to primary schools reveals that they have inadequate material, equipment, and human resources. According to Zafeirakou (2012), the situation in most centres is problematic and hopeless such that it is common sight to see young children learning under trees. Most primary schools which integrated ECD A and B did not improve their schools to be child friendly in terms of infrastructure and basic provisions. Children in such centres were found taking long turns and crowding to enjoy play equipment such as a see-saw as shown in Figure 1 below.

Lack of play materials, equipment, and toys was prevalent in both indoor and outdoor areas at most centres visited. Britto et al. (2011) posited that a vibrant early childhood programme should have a physical environment that reduces young children's exposure to accidents and unanticipated threats. Consistent with Figure 1 is the situation in Figure 2 below showing young children sleeping on home blankets they carry to school due to lack of appropriate furniture such as age appropriate chairs and desks as well as sleeping mattresses in the ECD classroom.

There is a need to worry about lack of quality in ECD because it contributes to a healthy and holistic development of a child. Good quality as well as 


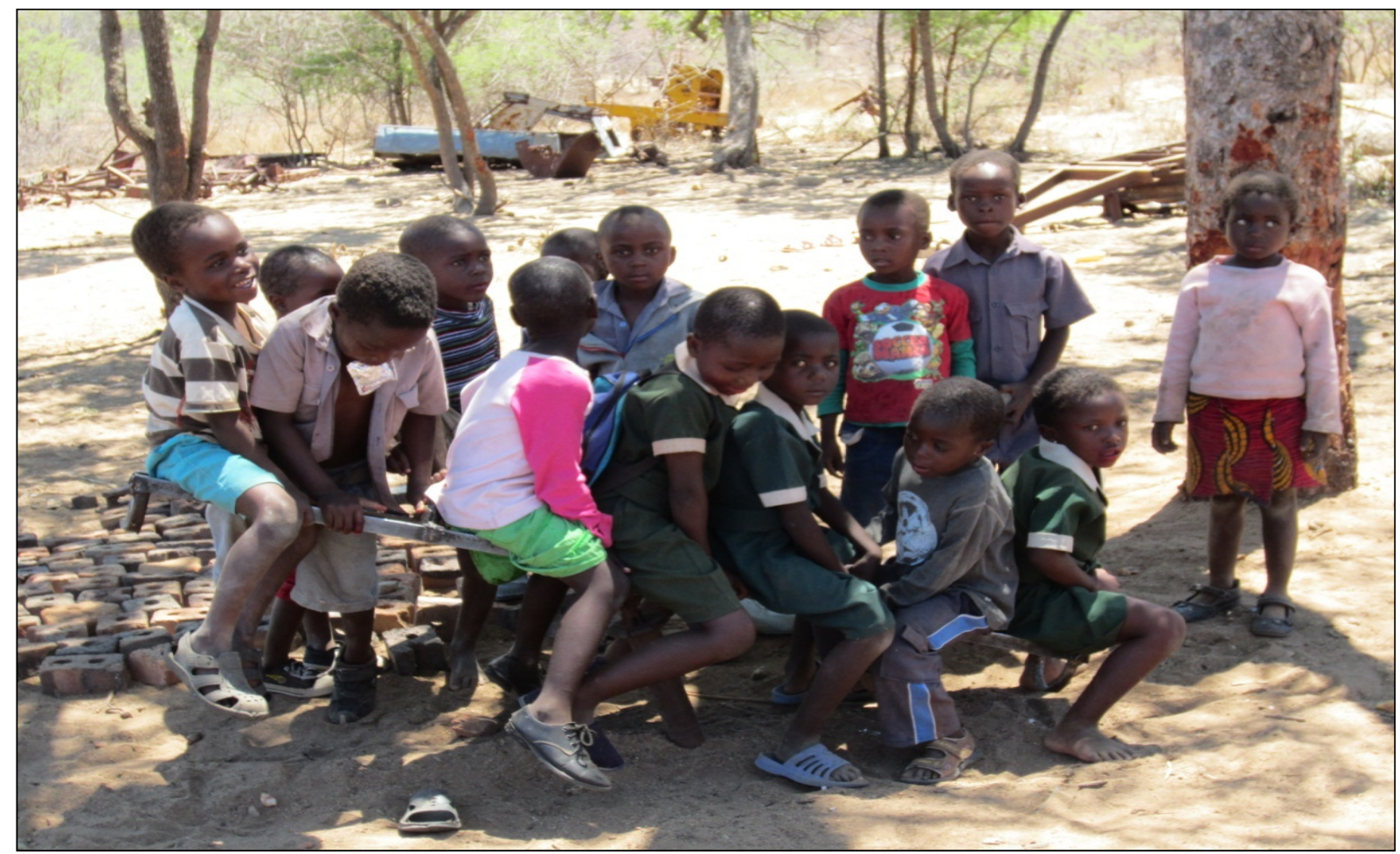

Figure 1. Gross Lack of Play Equipment at an ECD Centre.

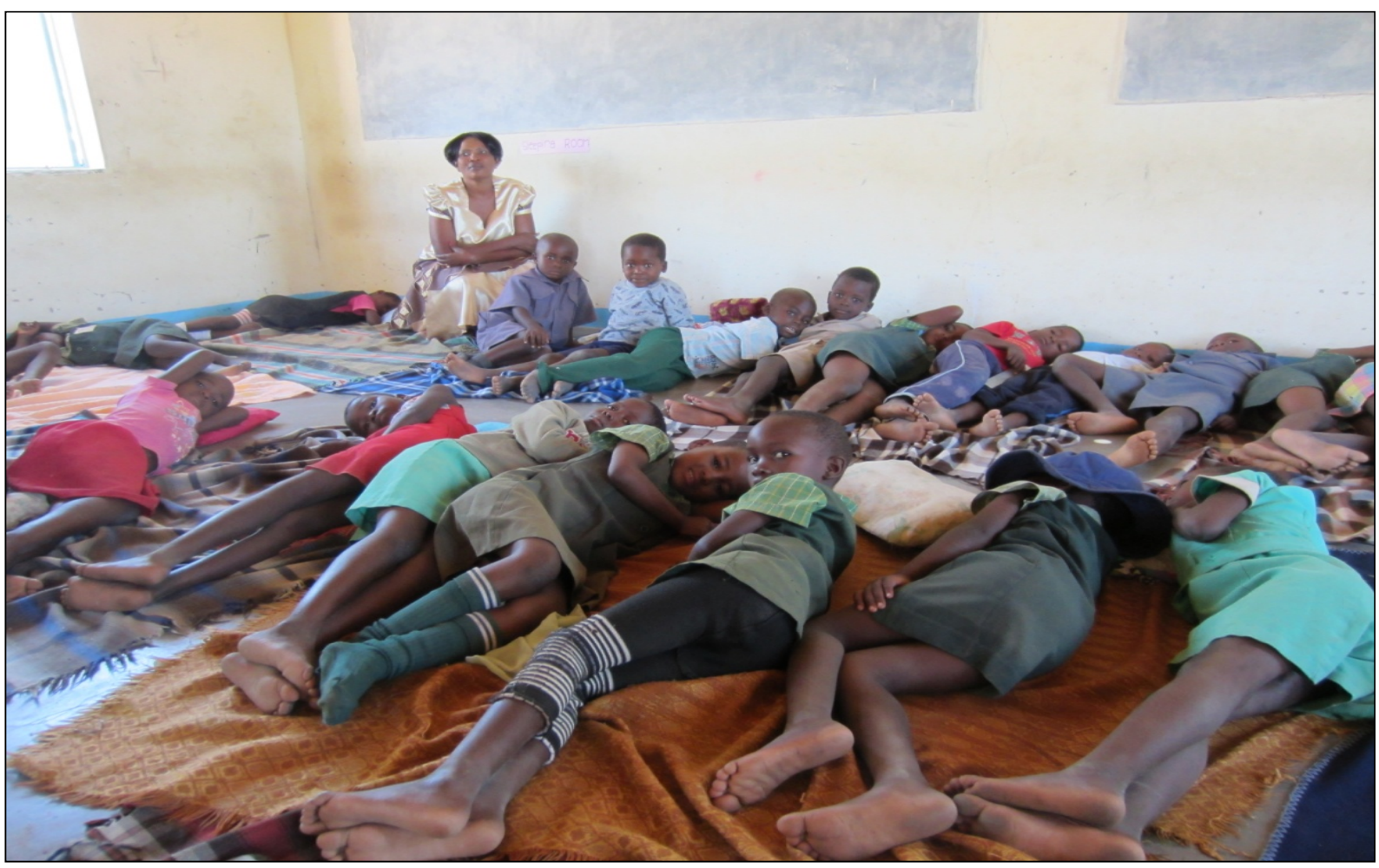

Figure 2. Lack of Appropriate Furniture in an ECD Classroom. 
affordable and accessible child care that meets the increasing needs of young learners is today's desired goal (Gordon and Browne 2012). In Zimbabwe, the ECD sub-sector continues to be deficient in achieving set benchmarks for total quality ECD services.

Most primary schools in urban, rural, farms, and mining communities have inadequate and inappropriate shelter, basic infrastructure and resources for young children aged 3-5 years old. The results reveal that some children in ECD programmes were housed in garages, backyard store rooms, cabins, under trees, unsanitary rooms, and in some of the ugliest buildings one can imagine. In some contexts, it was found that furniture and toilets used were not child size. On this issue, Mugweni (2011) viewed that infrastructure should be age appropriate and accommodative to all young learners regardless of their disability. Some of the shelters viewed were poorly ventilated there by putting young children's health at risk. The scenario enhanced quantity but compromised provision of quality services.

An analysis of the results shows that many young children in the ECD sub-sector in Zimbabwe are not benefiting from "education for all”. They do not have equity in educational provisions due to poor infrastructure, lack of qualified teachers, and sparsely populated centres especially in rural areas. In such areas, young children still walk long distances to school. It can be argued that in spite of notable progress in having young children accessed ECD provisions, statistics show that access remains extremely a limited utility and that quality is far below the expected level. Core benchmarks need to be attained so as to attain equitable access and quality rather than quantity of ECD provisions for social justice.

\section{Many Early Childhood Development Centres Did not Have Sufficient Water, Sanitation and Health (WASH) Facilities}

Zafeirakou (2012) found that in preschools, issues of sanitation remain unaddressed. Most ECD centres and primary schools do not have child size toilets, disinfections, and running water. Consistent with these findings, Gunhu, Mugweni, and Dhlomo (2011) earlier observed that most ECD centres in Bikita district lacked water, sanitation and health (WASH) facilities thereby compromising the quality of services. This depicts that quantity is more conspicuous than quality in young children's accessing of ECD provisions, thereby creating a quantity-quality dilemma in service delivery.

These findings are contrary to set benchmarks in SI 106 which states that one of the indicators that ensure quality in early childhood services is water and sanitation. The policy document SI 106 of 2005 spells out that at an ECD centre, there should be 1:12 young children per squat hall (in rural areas) and 1:6 children per flush water closet. The centres should have hand basins and running water available. There should also be proper storage of food, proper litter disposal, and age appropriate rest rooms (SI 106 of 2005).

\section{Lack of Trained ECD Specialists With Expertise in the Use of a Play-Based Curriculum}

It was found that most early childhood centres were manned by untrained paraprofessional. The scenario is a challenge towards the attainment of quality education in the sub-sector as it violates the hallmark of high-quality ECD programmes. Qualified teachers are a key factor in providing quality early childhood services (Hildebrand et al. 2000). The quality of interactions between the teacher and child is the single most important determinant of programme success (Zafeirakou 2012). Consistently, Young (2002) suggested that to enhance quality services, an early childhood teacher should have minimum professional qualification of at least a certificate, diploma, or degree. Consistently, Tassoni and Hucker (2005) averred that to effectively implement a play-based 
method which has a positive effect on the quality of ECD, it is important that all teachers involved are trained. The Secretary's Circular Number 14 of 2004 posits that ECD classes should be manned by qualified teachers so as to maintain high standards of service delivery. Indeed, experience has shown that trained ECD teachers are informed with the philosophy of developmentally appropriate practice in their praxis.

The results show that rural, resettlement, and farm ECD centres are served by untrained teachers. It was also found that the performance of trained teachers outweighs that of untrained staff and paraprofessionals in the execution of the ECD curriculum via a play-way method. Qualified practitioners are the key factors in providing high-quality care with most favourable and social outcomes for young children (Mugweni 2011). According to Zafeirakou (2012), an ECD programme requires personnel that have the requisite knowledge, skills, values, and attitudes to design, implement, monitor, assess, and develop activities appropriate to the age groups from birth to eight years old. It was also found that the socio-economic status of the country negatively affects the quality of ECD provisions in Zimbabwe.

\section{Inadequate Health and Nutrition Provisions}

In Zimbabwean public ECD classrooms, basic needs or health and nutrition of young children are not well met. On health matters, Santrock (2005) stated that every child should have sufficient provision of nutrition and safe drinking water. Consistent with the idea is the opinion by Gunhu et al. (2011) that every child in ECD settings has the right to clean WASH. In the authors' view, WASH improves the quality of ECD health services as well as improves the wellbeing of children and their families. The high prevalence of Soil-Transmitted Helminthiasis (STH) among young children in some centres researched was a challenge to the holistic provision of quality ECD.

The results are consistent with those of an earlier study. Mugweni (2011) found that many ECD centres in Zimbabwe do not provide food and health services to young children. In one of the districts surveyed in this study, it was found that only one primary school out of 37 with ECD attached to them had a feeding programme for young children. In the rest of the centres, children were expected to bring their own food from home regardless of their home background. It was observed that some of the children from poor livelihoods had no food to bring to school because there was not sufficient food at home. The practice compromised quality ECD service delivery.

\section{Large ECD Classes and Teacher-Child Ratios}

The SI 106 of 2005 stipulates that the teacher-child ratio in ECD classes should be 1:20. The national picture that emerged in the study was contrary to the stipulated benchmark. In some cases, ECD centres were seen to enrol up to 100 children under the custody of two untrained paraprofessionals. Most early childhood centres in high density townships were over-crowded thereby compromising quality caregiving. Teacher-child ratios in ECD centres attached to public primary schools ranged from 1:30 up to as many as 1:80. In some cases, untrained paraprofessionals manned two ECD classes with enrolments as large as 100 children. Such large classes enhance quantity but undermine quality in ECD provisions. Contrary to the finding, teacher-pupil contributes to quality performance since the teacher would consider each child's individual differences. Morrison (2012) posited that very large classes pose discipline challenges that are difficult to be contained by a teacher in such a situation. It should be noted that ratios and group sizes matter a lot in ECD centres. Indeed, the ratio of adult to the number of young children in a group or classroom is an important quality factor. More important is the total number of young learners in a group. These results violate benchmarks stipulated in SI 106 of 2005 that the ratio in ECD classes should be one teacher/caregiver to 20 children. 


\section{Unregistered ECD Centres}

Results revealed that there was mushrooming of private preschools in individual backyards in urban areas and rural service centres popularly known in Zimbabwe as Growth Points. Most of such centres were using the "Learning Through Play" ECD resource book, old syllabuses, and their own improvised curriculum documents. The practice compromised quality provision of services in the sub-sector. SI 106 of 2005 and Director's Number 48 of 2007 outline procedures and processes for registering ECD centres, it was found that this was not being adhered to by private ECD owners.

Despite the fact that the Principal Director's Circular Number 20 of 2011 gives strategies to curb the mushrooming of unregistered ECD centres, it was found that unregistered centres are still prevalent especially in urban areas. This is consistent to the earlier findings by Nherera (2011) and Nyandiya-Bandy (2000) that most ECD centres operating in Zimbabwe are not registered with the Ministry of Education, Sport, Arts and Culture. Nyandiya-Bandy (2000) also found that such centres had enrolments, staffing, and funding that tended to be unreliable thereby compromising quality. Such centres in most cases fail to comply with set standards regarding health, nutrition, safety, space, shelter, teacher qualification, and WASH requirements. According to Gunhu et al. (2011: 137), WASH in schools is the first step towards ensuring a quality health-learning environment and is important in lessening the spread of disease.

Still on challenges militating against quality provision of ECD services, it was observed that access remains limited especially in rural areas, resettlements and illegal settlements in peri-urban contexts (Makoni 2013). In most cases, children from low socio-economic backgrounds were the once deprived of quality early stimulation across all domains due to lack of access. It was observed that most early childhood centres in rural, resettlement, and farm areas are generally poorly equipped and resourced both in material and human (Dozva 2009).

\section{Parental Involvement}

The investigation identified that in most primary schools with ECD classes, parental involvement was evident but minimal. In some areas, it was found that parental involvement is not taken seriously. It should be noted that parental involvement is essential to access a high-quality education in the ECD sub-sector. Reviewed literature shows that a high-quality ECD programme involves parents and is sensitive to their needs and those of their children. At one of the ECD centres visited in Mashonaland East Province, parents collaborated with teachers and showed interest in the provision of ECD in primary schools. Morrison (2012) was of the opinion that the union of the family and the school in the matter of educational aims enhances young children's learning.

Consistently, Follari (2011) posited that a high-quality ECD programme involves parents in the learning of their children. This is because families are first environments which children interact with from birth. It should be noted that teachers of young children should collaborate with parents since they are the forerunners in the holistic development of the child, that is: physically, mentally, socially, morally, and creatively (Hildebrand et al. 2000). Overall, the study found that on issues of access, equity, and quality in the provision of ECD in Zimbabwe, urban ECD centres are congested due to rural-urban migration in search for better education services. Not withstanding the positive gains made in the ECD sub-sector, achieving quality early childhood services rests on access and equity. It should be noted that attaining equity in the provision of early education depends on access and quality which should always be in a state of homeostasis.

\section{Quality-Quantity Dilemma}

Overall, the study found that in terms of provision of 
ECD in Zimbabwe, there is a quality-quantity dilemma. It is envisaged that the dilemma will continue to persist in the ECD sub-sector unless the Zimbabwean economic environment improves. Quantity in education has been realized in Zimbabwe but attaining quality ECD provisions in most government schools in the near future will remain a myth. Henceforth, it is evident that quantity in the provision of ECD is downplaying achievement of quality education.

\section{CONCLUSIONS}

In conclusion, on issues of access, equity, and quality in ECD in Zimbabwe, there is a quantity-quality dilemma with quantity progress more prevalent than qualitative progress. Henceforth, for quality to be attained in the ECD sub-sector in Zimbabwe, there is need to positively address issues of access, equity, and quality. Regarding quality provisions in ECD in Zimbabwe, many gaps are to be filled if qualitative progress is to become more conspicuous than quantitative growth. Issues relating to access, equity, quality, and efficiency need to be considered in any quantitative expansion in education in Zimbabwe and elsewhere (Young 2002; Follari 2011). The quantitative expansion that has been noted in the Zimbabwean ECD sub-sector has to be treated with caution so that a balance is achieved with quality ( $\mathrm{T}$. Mufanechiya and A. Mufanechiya 2011). The study also identified that the existing policies on ECD provision need to be effectively implemented in both government and private settings in order to improve children's access, equity, and quality education as well as improve the growth and development of the ECD sub-sector in Zimbabwe.

To improve the quality and capacity of teacher educators, there is need for the Ministry of Higher and Tertiary Education to train effective local ECD teachers/caregivers and also facilitate the development and use of play/learning materials by such teachers.
Capacity building of ECD teachers helps strengthen children's transition within ECD classes to primary school grades.

The activities of government, non-governmental organizations, government ministries, United Nation agencies, the private sector, cooperating agencies, parents, and the donor community should indicate a high sense of commitment to the ECD programme in Zimbabwe so as to attain quality provisions. However, it should be noted that the unstable macro-economic environment and the fall of the Zimbabwean dollar against major currencies have negatively impacted the implementation of ECD and the achievement of the national aims as outlined in the policy documents. Regardless of the phenomenal expansion of the education sector after independence, quality and access to ECD remain inadequate in some areas of Zimbabwe. The significant aspect is to maintain a state of balance between quantity and quality services.

\section{References}

Britto, P. R., H. Yoshikwa, and K. Boller. 2011. "Quality of Early Childhood Development Programs in Global Contexts: Rationale for Investment, Conceptual Frame Work and Implications for Equity.” Social Policy Report 25(2):1-31.

Creswell, J. W. 1994. Research Design: Qualitative and Quantitative Approaches. London: Sage.

—. 2003. Research Design: Qualitative, Quantitative and Mixed Methods Approaches. London: Sage.

- 2007. Qualitative Inquiry and Research Design: Choosing Among Five Approaches. London: Sage.

De Vos, A. S., H. Strydom, C. B. Fouche, and C. S. L. Delport, eds. 2005. Research at Grass Roots: For the Social Sciences and Human Service Professions. 3rd ed. Hatfield, Pretoria: Van Schaik.

Dozva, M. 2009. "Strategies Used by Chitungwiza Day Care Centre Caregivers to Deal With Separation Anxiety in Preschool Children." Zimbabwe Journal of Educational Research 21(3):358-374.

Follari, L. M. 2011. Foundations and Best Practices in Early Childhood Education: History, Theories and Approaches to Learning. New York: Heinemann.

Gordon, A. M. and K. W. Browne. 2012. Beginnings and Beyond: Foundations in Early Childhood Education. 9th ed. 
New York: Delmar Publishing Inc.

Government of Zimbabwe. 1996. Education Act. Ministry of Education, Sport, Arts and Culture. Harare: Government Printers.

- 2000. Zimbabwe National Action Plan 2000. Harare: Government Printers.

—. 2004. Secretary's Circular Number 14 of 2004. Ministry of Education, Sport, Arts and Culture. Harare: Government Printers.

—. 2005. Statutory Instrument 106 of 2005. Ministry of Education, Sport, Arts and Culture. Harare: Government Printers.

Gunhu, M. R., R. M. Mugweni, and T. Dhlomo. 2011. "Integrating Early Childhood Development (ECD) Into Mainstream Primary School Education in Zimbabwe: Implications to Water, Sanitation and Hygiene Delivery.” Journal of African Studies and Development 3(7):135-137.

Hancock, D. R. and B. Algozzine. 2006. Doing Case Study Research: A Practical Guide for Beginning Researchers. New York: Teachers College Press.

Hildebrand, V., L. A. Phenice, M. M. Gray, and R. P. Hines. 2000. Knowing and Serving Diverse Families. Columbus, OH: Pearson, Merrill.

Hill, S. and T. Chalaux. 2011. "Improving Access and Quality in the Indian Education System." OECD Economics Department Working Papers, No. 885, OECD Publishing.

Hyde, K. A. L. and S. Miske. 2000. "Education for All 2000 Assessment, Thematic Studies: Girls' Education.” Presented at the World Education Forum, 26-28 April, 2000, Dakar, Senegal.

Makoni, R. 2013. Evaluation of the National Early Childhood Programme. Harare: UNICEF.

Morrison, G. 2012. Early Childhood Education Today. 12th ed. New York: Pearson.

Mufanechiya, T. and A. Mufanechiya. 2011. "Motivating Zimbabwean Secondary School Students to Learn: A Challenge." Journal of African Studies and Development 3(5):96-104.

Mugweni, R. M. 2011. Review of the Education Transition Fund and Early Childhood Development Sub-Sector Analysis. Harare: European Commission, AESA Consortium.

—. 2012. "Secondary School Teachers' Conceptualization and Implementation of the AIDS Action Programme in Zimbabwe.” Unpublished $\mathrm{PhD}$ thesis, University of Pretoria.

Mugweni, R. M. and F. E. Dakwa. 2013. "Exploring the Implementation of 'Education for All' in Early Childhood
Development in Zimbabwe: Successes and Challenges.” International Journal of Case Studies 2(10):1-9.

Nherera, C. 2011. Educational Provisions in Zimbabwe: Issues and Challenges. Pretoria: OSSREA.

Nwonwu, F. 2008. Millennium Development Goals: Achievements and Prospects of Meetings the Targets in Africa. Pretoeia: Africa Institute of South Africa.

Nyandiya-Bandy, S. 2000. Child Care Practices in Zimbabwe. Harare: Ministry of Education, Sport, Arts and Culture.

Santrock, J. W. 2005. Children. 6th ed. New York: McGraw-Hill.

Shizha, E. and M. T. Kariwo. 2012. Education and Development in Zimbabwe: A Social, Political and Economic Analysis. Boston: Sene Publishers.

Silverman, D. 2010. Doing Qualitative Research: A Practical Handbook. 3rd ed. London: Sage.

Tassoni, P. and K. Hucker. 2005. Planning Play and the Early Years. Oxford: Heinemann.

Thomas, M. L. 2010. "The Variations and Strategies of Faith-Based Advocacy Organizations in Virginia.” Journal of Policy Practice 9(3/4):240-262.

Tinto, V. 2012. Completing College: Rethinking Institutional Action. Chicago, IL: Chicago Press Books.

Vernez, G., R. Krop, and C. P. Rydell. 1999. Closing the Education Gap: Benefits and Costs. New Yourk: RAND Corporation.

Young, M. E. 2002. From Early Child Development to Human Development: Investing in Our Children's Future. Washington, D.C.: World Bank.

Zafeirakou, A. 2012. "The Quest for Access, Quality and Equity in Early Childhood Education (ECE).” Presented at the Global Partnership for Education/UNICEF Regional Workshop, June 4-6, 2012, Athens, Greece.

\section{Bio}

Rose M. Mugweni, Doctor of Philosophy in Education Policy Studies (University of Pretoria, South Africa), Master of Education in Early Childhood Education (University of Newcastle, Australia), Barchelor of Education in Early Childhood Education (University of Zimbabwe), Diploma in Education (University of Zimbabwe), Department of Educational Foundations, Great Zimbabwe University, Zimbabwe; research fields: contemporary issues in early childhood education, HIV and AIDS and adolescent health, parenting and early stimulation, education policy issues, vulnerable children. 